certainly have to include a full-scale investigation of suspension characteristics as affecting a person lying on a stretcher.

Where commercial incentives are lacking, Government departments have spent large sums on various research and development programmes carried out by private industry. Specialized Army vehicles are a case in point. A car manufacturer accepting such a contract for ambulance development would be encouraged to make use of available components already in large-scale production to the maximum extent compatible with meeting the specified requirements. Even so, the selling price of a vehicle developed in this way would undoubtedly be higher than at present; but in terms of fitness for the job it could be immensely superior to cheaper competitors. For this reason it might well find export customers to supplement the limited home demand, because the ambulance problem is not unique to Great Britain.

\section{Review of Doctors' Pay}

The latest report of the Review Body on Doctors' and Dentists' Remuneration ${ }^{1}$ will disappoint many doctors. Not surprisingly, perhaps, the Prime Minister announced on 7 May his acceptance of it in entirety. Special meetings of the profession's representatives are being called to consider the report.

It will be seen from the summary published at page 360 that the main recommendations are for small increases in expense allowances for general practitioners, 5.5 to $8.5 \%$ increases in the salary scale of medical assistants, and a slight increase in the number of distinction awards. Thus the claims put forward by the B.M.A. in its evidence, published this week in the Supplement at page 127, are almost entirely rejected. A particularly notable omission is any recommendation to increase the pay of senior registrars, who received little benefit from the previous report. The Review Body argues that its previous awards were intended to set a level of remuneration somewhat above the right level at the beginning of the period 1966-8, in the expectation that the level would then be a little lower than it should be by the date of its next review. The report suggests that the incomes standstill, the period of severe restraint, and devaluation could not have been foreseen, and that the annual rate of increase in wages and salaries from 1966 to 1968 was less than the Review Body had expected. So it concludes that the levels of doctors' pay in April 1968 were higher than had been intended in relation to other salaries ; no immediate adjustment was therefore needed; and that as economic conditions in Britain could not be foreseen no recommendations would be made for the future. If at any time in the future the Review Body felt that an immediate general increase was needed it would recommend one.

When the Review Body was set up in 1962 its establishment followed years of contention between Government and profession, whose aims were identical in that each side sought to provide the best possible health service but whose interests diverged. In holding the balance between profession and public the Review Body has been generally regarded as fair and just, so that the undertaking given in its latest report to keep doctors' pay under continuous review will be welcomed.

\footnotetext{
'Review Body on Doctors' and Dentists' Remuneration : Ninth Report, 1968, Cmnd. 3600. H.M.S.O.

${ }^{2}$ Royal Commission on Medical Education, 1965-68: Report, 1968, Cmnd. 3569. H.M.S.O.
}

But what of its present recommendations-or lack of them ? These have to be seen against a background of deficiencies and overwork in many parts of the Service.

The recently published report of the Royal Commission on Medical Education, ${ }^{2}$ for example, states that Britain is likely by 1975 - only seven years hence-" to be some 11,000 short of the number of practising doctors necessary to maintain the National Health Service at a satisfactory level on its present basis." Clearly something more than better pay is needed to remedy that state of affairs, but competing as we must in an international market where our own graduates receive attractive offers from overseas, and take them, the remuneration attainable in Great Britain must play its part in holding them here. Moreover, though the Review Body is rather cool about the burden of work in clinical practice, it is worth noting that the Royal Commission did frankly acknowledge "the disheartening increase in frustration and overwork," and recognized the need for improved terms of service to stop the flow of emigration.

The medical profession cannot expect, and nor does it wish, to be released from financial strictures imposed equitably on every part of the community. But at the same time it is uncomfortably aware that unless a proper value is placed on its work the Health Service, and with it the career of medicine, will gradually deieriorate. Some would argue that it already shows signs of doing so. Since the Health Service exercises a nearly complete monopoly, comparisons with practice outside it, at least in Great Britain, are virtually meaningless, yet the determination of what is a "proper value " poses a problem that cannot be solved simply in terms of productivity, turn-over, economy, and other criteria beloved of statisticians. To some extent the Review Body recognizes this when it states: "But if the professions" remuneration were allowed to fall seriously behind, then, apart from the question of equity, the problems of manpower and morale which the recommendations in our Seventh Report were intended to help to solve would recur, to the serious and lasting detriment of the National Health Service."

\section{Young Volunteers}

Despite the publicity that is apt to attend evidence to the contrary, a desire for service to others is widespread among young people. This gratifying fact is not surprising, for human nature does not change-only the environments in which it functions. What is not always appreciated is that in modern civilized societies, with their highly organized systems of social security, the need for voluntary community service does not lessen, and yet the will to serve is too often frustrated for lack of a clear objective or of ways to achieve it.

Therefore the Government's initiative in promoting a "Young Volunteer Force Foundation" is to be warmly welcomed. Constituted as a charitable trust, the foundation's purpose will be to help local and hospital authorities and voluntary organizations in making more effective the contacts between the volunteers on the one hand and the community on the other. It is to have a full-time staff of young people experienced in or with an aptitude for community service, and an advisory body to turn to for advice. The foundation will work mainly through teams sent on request to promote local efforts and by providing a consultancy and information service. 